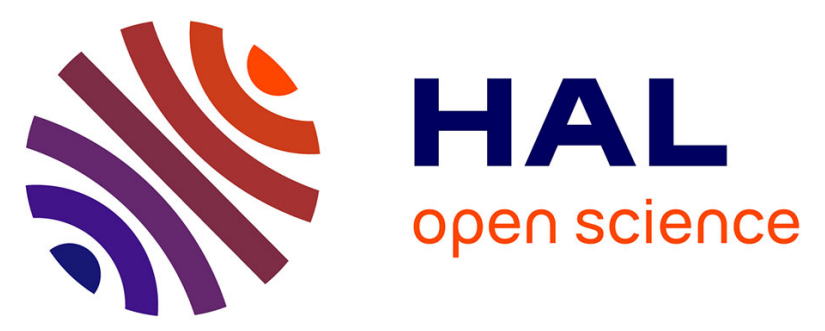

\title{
Impact of UV-C radiation applied during plant growth on pre- and post-harvest disease sensitivity and fruit quality of strawberry
}

Marine Forges, Marc Bardin, Laurent Urban, Jawad Aarrouf, Florence Charles

\section{To cite this version:}

Marine Forges, Marc Bardin, Laurent Urban, Jawad Aarrouf, Florence Charles. Impact of UV-C radiation applied during plant growth on pre- and post-harvest disease sensitivity and fruit quality of strawberry. Plant Disease, 2020, 104, pp.3239-3247. 10.1094/PDIS-02-20-0306-RE . hal-02883862

\section{HAL Id: hal-02883862 \\ https://hal.inrae.fr/hal-02883862}

Submitted on 9 Jun 2021

HAL is a multi-disciplinary open access archive for the deposit and dissemination of scientific research documents, whether they are published or not. The documents may come from teaching and research institutions in France or abroad, or from public or private research centers.
L'archive ouverte pluridisciplinaire HAL, est destinée au dépôt et à la diffusion de documents scientifiques de niveau recherche, publiés ou non, émanant des établissements d'enseignement et de recherche français ou étrangers, des laboratoires publics ou privés.

\section{(1) (1) $\$$}

Distributed under a Creative Commons Attribution - NonCommercial - NoDerivatives 44.0 
1 Impact of UV-C radiation applied during plant growth on pre- and

2 post-harvest disease sensitivity and fruit quality of strawberry

3

4 M. Forges $^{1^{*}}$, M. Bardin ${ }^{2}$, L. Urban ${ }^{1}$, J. Aarrouf ${ }^{1}$, and F. Charles ${ }^{1}$

5

$6{ }^{1}$ Unité Mixte de Recherche Qualisud, Laboratoire de Physiologie des fruits et Légumes,

7 Université d'Avignon, 301 Rue Baruch de Spinoza, BP2139 - 84916, Avignon, France

8 2INRAE, Pathologie Végétale, F - 84140, Montfavet, France

9 Corresponding author: M. Forges; Email: marine.forges@gmail.com

10 


\section{Abstract}

22 Forges, M., Bardin, M., Urban, L., Aarrouf, J., and F. Charles 2020. Impact of UV-C radiation 23 applied during plant growth on pre- and post-harvest disease sensitivity and fruit quality of 24 strawberry. Plant Dis.

UV-C radiation is efficient in reducing the development of diseases in many species,

27 including strawberry (Fragaria $x$ ananassa). Several studies suggest that UV-C radiation is effective not only because of its disinfecting effect but also because it may stimulate plant defenses. In this study, the effect of pre-harvest UV-C radiation applied during strawberry cultivation on plant growth, fruit quality and susceptibility to major fungal diseases, as gray mold, powdery mildew and soft rot, was evaluated. UV-C treatments had an impact on flowering initiation and fruit development. Flowering occurred earlier for UV-C-treated plants than for non-treated plants. At harvest, a larger amount of fruit was produced by treated plants despite their slight decrease in leaf area. UV-C treatment did not improve strawberry shelf life but did not alter the physical integrity of strawberry fruit. Natural infection of leaves to powdery mildew and of fruit to Rhizopus was strongly decrease in response to UV-C treatment. Keywords: strawberry, UV-C, pre-harvest, post-harvest, phytopathology, quality 


$\begin{array}{ll}\text { AUDPC } & \text { Area under disease progression curve } \\ \text { AUFC } & \text { Area under fluorescence curve } \\ \mathrm{F}_{0} & \text { Initial fluorescence } \\ \mathrm{F}_{\mathrm{M}} & \text { Maximal fluorescence } \\ \mathrm{N} & \text { Newton } \\ \text { PAL } & \text { Phenylalanine ammonia-lyase } \\ \text { PDA } & \text { Potato dextrose agar } \\ \text { PSII } & \text { Photosystem II } \\ \text { SOD } & \text { Superoxide dismutase } \\ \text { UV-C } & \text { Ultraviolet-C }\end{array}$



characteristics (Li et al., 2017; Lu et al., 2018). In addition, strawberries are one of the richest

sources of natural antioxidants and therefore have a highly beneficial effect on human health (Hannum, 2004; Li et al., 2019; Yan et al., 2019). However, many plant pathogenic microorganisms, including fungi, are very damaging to both strawberry plants and fruit. Yields can be strongly affected by these fungi, and strawberries are subjected to rapid degradation, affecting fruit flavor (Perkins-Veazie, 1995). Restrictions on the use of fungicides make it necessary to find alternative phytosanitary tools. Among these tools, physical methods can improve the resistance of plants to pathogens and can increase the synthesis of vitamins, micronutrients and secondary metabolites in fruit (Aghdam et al., 2018; Li et al., 2014; Poiroux-Gonord et al., 2010). Among these physical methods, the application of low doses of ultraviolet-C (UV-C) radiation creates a moderate oxidative stress that can increase the resistance of the plants to plant pathogens (Charles et al., 2008; Mercier et al., 2001; Ouhibi et al., 2015; Vasquez et al., 2017) and improve the nutritional qualities of plant products (Mohammadi et al., 2012; Xu et al., 2019b).

The lethal effect of UV-C light has been exploited successfully to control post-harvest diseases, thus extending the shelf life of fruit and vegetables (Charles et al., 2008; Erkan et al., 2008; Liu et al., 1993; Maharaj et al., 1999; Mercier et al., 2001; Siddiqui et al., 2011; Urban et al., 2016). UV-C irradiation has been extensively studied for its role in the reduction of postharvest disease spoilage in harvested horticultural products by exerting a direct germicidal effect and/or by eliciting critical defense responses (Duarte-Sierra et al., 2019). For instance, it can induce partial resistance to the plant pathogenic fungus Botrytis cinerea on carrots, lettuce, tomatoes and strawberries (Charles et al., 2008; Mercier et al., 1993a,b; Ouhibi et al., 2014; Pombo et al., 2011). In the case of strawberry, the enhancement of resistance to $B$. 
cinerea was linked to an increase in the activity of phenylalanine ammonia-lyase (PAL) and polyphenol oxidase and in the expression of pathogenesis-related protein genes (Pombo et al., 2011). Moreover, UV-C radiation can induce defense mechanisms, increasing the content of chitinase and superoxide dismutase (SOD) or PAL in various fruit, such as mangoes, peaches and strawberries (El-Ghaouth et al., 2003; Erkan et al., 2008; Gonzalez-Aguilar et al., 2007; Mohammadi et al., 2012; Yang et al., 2014). Several studies have also pointed out that UV-C light can influence the physiology of harvested organs, delaying their senescence and stimulating secondary metabolism (Xu et al., 2018), which is known to play a role in both the health benefits of the harvested organs and the defense of plants against pathogens (Huang et al., 2017; Poiroux-Gonord et al., 2010). UV-C radiation caused modifications in the secondary metabolites of mangoes, grapes and peaches compared to those in non-treated fruit (Freitas et al., 2015; Gonzalez-Aguilar et al., 2001, 2004). In strawberry, UV-C radiation applied at the post-harvest stage induced beneficial effects on the preservation and promotion of fruit quality, including a delay in fruit softening through reduced cell wall degradation (Pombo et al., 2009) or a stimulation of the biosynthesis of bioactive molecules, such as anthocyanins, ascorbic acid and esters (Severo et al., 2015). In addition to these compounds, UV-C radiation applied to strawberry fruit at the post-harvest stage caused variations in the activation of genes involved in fruit firmness, thus allowing an improvement in the shelf life and in the production of volatile compounds, which results in strongly aromatic fruit (Severo et al., 2015).

UV-C treatment of growing plants has an effect on the resistance of vegetative organs to pathogens (Obande et al., 2011; Xu et al., 2017b). Janisiewicz et al. (2016) demonstrated that pre-harvest UV-C treatment could be an effective way to manage gray mold (caused by B. cinerea) in the production of strawberry. On strawberries, UV-C radiation at $12.36 \mathrm{~J} / \mathrm{m}^{2} \mathrm{did}$ 
100

101

102 103

104

105

106

107

108

109

110

111

\section{Materials and Methods}

\section{Plant material}

not impact photosynthesis or pollen tube germination (Janisiewicz et al., 2016). In geranium (Pelargonium $x$ hortotum), low doses of UV-C radiation $\left(0.5-5.0 \mathrm{~kJ} / \mathrm{m}^{2}\right)$ applied during growth caused photomorphogenic changes such as an increase in biomass and in the number of lateral stems and inflorescences (Darras et al., 2012a).

To our knowledge, only a few reports have evaluated the potential of low doses of UVC applied during plant growth for use in fruit or vegetable and ornamentals quality maintenance (Darras et al., 2012a; Janisiewicz et al., 2016; Obande et al., 2011 ; Severo et al., 2016; Xie et al., 2015 ; Xu et al., 2019a). However, a recent comprehensive review by Urban et al. (2016) discussed the physiological effects of UV-C radiation and evaluated its agronomic potential at both the pre-harvest and post-harvest stages. It is important to verify that the improvement in plant resistance resulting from UV-C treatments does not negatively impact yield or fruit quality at harvest and during post-harvest storage.

The aim of this study was to evaluate the effect of UV-C treatments applied to strawberry plants (i) on the resistance of leaves and fruit to the main fungal pathogens of strawberry as gray mold, powdery mildew and soft rot, (ii) on the vegetative growth of the plant and crop yield and (iii) on the quality of strawberry fruit after harvest.

Trays of strawberry plants of the cultivar Candiss (single-harvest plants, Ciref, France) supplied by the Martaillac nursery (Sainte-Marthe, France), were transplanted in a mixed substrate (60\% compost of TS3 type (Code of Practice) with fine granulometry and $40 \%$ pine 
122

124

126

Strawberry plants were treated once a week after two weeks of adaptation in the greenhouse.

141 Several modes of application were tested:

142

bark) and placed in a greenhouse at the end of February. The plants were fertilized with a standard commercial nutrient solution (Soluveg Parme, NPK 16-6-27+3 MgO+OE, Angibaud Derome) with a drip irrigation system (one dripper per pot) at a frequency adapted to the climatic demand. Plants were completely randomized $(n=188)$ and were grown for 3 months from planting to harvesting of mature fruit. Plants were grown for two weeks after transplantation for adaptation to the greenhouse. One week later, flowers appeared.

The experiment was carried out twice: in 2017 and 2018. The fruit were harvested at the beginning of May when they reached the stage of commercial maturity (completely developed, intense red color and firm). Strawberry fruit were harvested only once.

\section{UV-C treatments}

The device used for UV-C treatments was a luminous ceiling with 9 UV-C lamps (DSP UV-C tube, OSRAM HNL, 24 W; Pascal et al., 2018). The measurement of the spectrum (by a UV sensor, OSI UV-20 TO-8 photodiode) confirmed a major peak at $254 \mathrm{~nm}$. Four plants were processed in the box at the same time at a distance of $40 \mathrm{~cm}$ from the UV-C lamps.

The dose applied to the plants was calculated based on light intensity and time of exposure. Light intensity measurements were performed with a radiometer positioned $40 \mathrm{~cm}$ below the ceiling lights. The UV-C dose selected was $1.70 \mathrm{~kJ} / \mathrm{m}^{2}$ (i.e., a treatment time of 4 min $08 \mathrm{sec}$ ) according to a study carried out by Forges et al. (2018).

- Before flowering, "BEFORE" (1 x $\left.1.70 \mathrm{~kJ} / \mathrm{m}^{2}=1.70 \mathrm{~kJ} / \mathrm{m}^{2}\right)$,

- After flowering, “AFTER" (5 x $\left.1.70 \mathrm{~kJ} / \mathrm{m}^{2}=8.50 \mathrm{~kJ} / \mathrm{m}^{2}\right)$, 
- During growth “DURING” $\left(6 \times 1.70 \mathrm{~kJ} / \mathrm{m}^{2}=10.20 \mathrm{~kJ} / \mathrm{m}^{2}\right)$,

- No treatment: “CONTROL".

146

There were 47 strawberry plants per treatment modality. Following each irradiation

147 treatment, the treated plants were kept in the dark overnight.

148

150

151

152

153 machinery. All the parameters measured in this study were explained by Stirbet and Govindge

166 (2011). The area under the fluorescence curve (AUFC) was calculated during plant growth. 
167

168

169

170

171

172

173

174

175

\section{Morphological analysis during plant growth}

To characterize strawberry plant growth, the number of leaves on each strawberry plant was counted $(n=47)$ before the first UV-C treatment (i.e., 15 days after planting the tray plants) and at harvest (after 8 weeks of growth). The leaf area was also measured at harvest on one leaf of each strawberry plant $(n=47)$. This leaf was selected since the beginning of experiment marked by a ring corresponding to young leaf above the plant cover.

For the fruit production phase, counting of buds, flowers and green/turning/mature fruit was carried out each week (from flowering to the harvest day, which gives an enumeration of 6 consecutive weeks) on each strawberry plant $(n=47)$. These data provide information about the impact of the UV-C treatments on flowering and fruit production. At harvest, the strawberry fruit were weighed $(n=20)$.

\section{Fungal material and pathological tests on leaves and fruit}

Strain Bc1 of Botrytis cinerea was used in this study to artificially inoculate leaves and fruit. This strain was chosen because it is very aggressive on strawberry as already observed by Forges et al. (2018). Test was done on detached leaves fully developed and above the plant cover. For pathological tests on leaves, the strain was grown for 3 days on PDA medium (potato dextrose agar, $39 \mathrm{~g} / \mathrm{L}$, Sigma-Aldrich) at $21^{\circ} \mathrm{C}$ (16 h of light and $8 \mathrm{~h}$ in dark). Mycelial plugs of $0.5 \mathrm{~cm}$ diameter were used as inoculum and deposited on the central veins of leaves $(n=47)$. Lesions caused by the fungal pathogen were monitored for a whole week on a dayper-day basis by taking pictures and measuring the lesion areas with ImageJ software. The area under the disease progress curve (AUDPC) was then computed to determine the level of sensitivity of the strawberry plants to the pathogen. 

dosed at $10^{6}$ spores $/ \mathrm{mL}$ thanks to Malassez counting cell. Each fruit was wounded on the

epidermal surface with a sterile needle, and $10 \mu \mathrm{L}$ of spore suspension was applied. The inoculated fruit were stored in plastic boxes at $21{ }^{\circ} \mathrm{C}$ in the dark. The disease development was estimated by counting the number of diseased fruit and by taking pictures for 5 days after inoculation and calculating the fruit lesion area by using ImageJ software.

Natural infections by pathogens were also observed during the two years of experiments (2017 and 2018) and were evaluated. A natural epidemic of powdery mildew caused by Podosphaera aphanis occurred in 2017. During fruit production, the number of leaves with visible typical symptoms of powdery mildew (as exemplified in Bardin and Gullino, 2020) was counted, and the percentage of infected leaves (with more than 3 spots on leaves) per plant was computed ( $n=47$ plants per treatment modality). Natural infection of fruit by B. cinerea (see Bardin and Gullino, 2020) was also observed in 2018 and infected fruit were counted on each plant before harvesting. The percentage of strawberry plants with at least one infected fruit was computed ( $n=47$ plants per treatment modality). During storage, fruits naturally infected by Rhizopus sp. were counted during the two years of the experiment, and the percentage of infected fruit was computed ( $n=18$ fruit per treatment modality).

\section{Quality analysis of fruit during post-harvest storage}

The firmness and color of fruit ( $n=18$ fruit per treatment modality) were estimated after harvest (D0) and after 2 (D2) and 4 days (D4) of storage at $21^{\circ} \mathrm{C}$.

Fruit firmness was carried out on the domed part of the strawberry with a penetration probe ( $5 \mathrm{~mm}$ diameter). The force required for the probe to penetrate the fruit was measured 
211 by a Penefel texture analyser (Setop Giraud-Technologie, France). The firmness was reported 212 as force in Newtons (N).

214 calibrated with a white reference plate, and the parameters $L^{*}, a^{*}$ and $b^{*}$ were measured.

215 Hue angle $\left(\mathrm{H}^{\circ}\right.$, where $0^{\circ}=$ red-purple, $90^{\circ}=$ yellow, $180^{\circ}=$ bluish-green, and $270^{\circ}=$ blue $)$ and 216 chroma ( $\mathrm{C}^{*}$, which represents the intensity of color) were estimated according to McGuire 217 (1992).

To evaluate consumer preferences, taste tests were carried out on harvested

219 strawberry fruit. A panel of 30 consumers, with a combination of men and women, tasted 220 strawberry fruit from plants undergoing the various UV-C treatments. Consumers tasted blind 221 and had to indicate their preferences and taste criteria (such as acidity, sweetness or texture).

\section{Data Analysis}

224 data normality was performed using the Shapiro test. If the data were normal, an analysis of variance (ANOVA) was performed. In the case of a significant effect of the test factor, a comparison of means was made with Duncan's test or Newman-Keuls test. In contrast, if the data were not Gaussian, nonparametric tests were used, such as the Kruskal-Wallis test. For each test, a threshold of $p$-value $<0.05$ was used. All statistical analyses were performed on

229 all results obtained in both 2017 and 2018 years.

\section{Results}


plants, the number of leaves was counted before the first UV-C treatment and at harvest, 8 weeks after planting (Figure 1-A). Plant growth was homogeneous before the first UV-C treatment. At harvest, no significant differences in the number of leaves was observed between treated groups and non-treated group. However, leaf area was significantly smaller in the plants treated after flowering ("AFTER" and "DURING") compared to the non-treated plants ("CONTROL") and the plants treated once before flowering ("BEFORE") (Figure 1-B).

evaluate the impact of the UV-C treatments on the plant photosystem (Figure 2). Successive applications of UV-C did not cause any major damage to the photosynthetic apparatus of strawberry plants. In fact, the different percentages observed between each group treated with UV-C and the control group did not exceed $25 \%$. We observed that the measured parameters associated with the fluorescence of chlorophyll a increased for plants treated before flowering ("BEFORE") and decreased for plants treated after flowering ("AFTER") or during cultivation ("DURING") compared to the non-treated group ("CONTROL").

Impact of UV-C treatments on strawberry fruit development

The number of buds was significantly lower in the UV-C-treated plants than in the nontreated plants (Figure 3-A). Conversely, at the same time, the number of flowers was

251 significantly higher for strawberry plants that received UV-C treatment (1.5 to 2 flowers per 252 plant depending on the treatment) than in the plants that were not treated ( 0.25 flowers per 253 plant for the "CONTROL") (Figure 3-B). 
256 "DURING" modalities, than in non-treated plants ("CONTROL"). After 4 weeks, all treated 257 samples, including "BEFORE", "DURING" and "AFTER" plants, had more green fruit than the 258 control. Then, after 5 weeks, the number of green fruit produced per plant was similar across 259 all modalities.

The number of ripe fruit per plant was counted on the day of harvest (Figure 5-A). The amount of ripe fruit was significantly higher for the plants treated with UV-C before flowering

262 ("BEFORE" with a mean of 6.6 ripe fruit per plant) or during the entire cultivation process 263 ("DURING" with a mean of 5.5 ripe fruit per plant) than for the non-treated plants ("CONTROL" 264 with a mean of 3.8 ripe fruit per plant) and those treated after flowering ("AFTER" with a mean 265 of 4.5 ripe fruit per plant). An approximately two-fold increase in the amount of ripe fruit was 266 observed when the plants were UV-C treated. Moreover, UV-C treatment applied before 267 flowering ("BEFORE") significantly increased the weight of the fruit at harvest (Figure 5-B).

\section{Impact of UV-C treatments on strawberry sensitivity (leaves and fruit) to B. cinerea}

Pathogenicity tests using $B$. cinerea on detached leaves fully developed and above the

270 cover of strawberry plant collected at harvest revealed a significant reduction in the 271 susceptibility to the plant pathogen (19\%) for the plants that were treated with UV-C after 272 flowering ("AFTER") (Figure 6-A). For plants treated before flowering, the sensitivity to $B$. 273 cinerea significantly increased up to $25 \%$ compared to the non-treated plants ("CONTROL"). No difference in the sensitivity to $B$. cinerea between fruit collected from UV-C-treated 275 plants or untreated plants was observed (Figure 6-B). However, a tendency (not significant) 276 for an increase in the sensitivity of strawberry fruit after UV-C treatment was observed.

277 Impact of UV-C treatments on strawberry sensitivity (leaves and fruit) to spontaneous 278 infections 

aphanis) occurred a few days before harvest. We evaluated the level of strawberry resistance against this biotroph by counting the infected leaves (Figure 7). UV-C treatment, regardless of the period of application, significantly decreased the susceptibility of strawberry plants to the pathogen by $51 \%, 59 \%$ and $75 \%$ in the "BEFORE", "AFTER" and "DURING" treatments, respectively.

At harvest, some strawberry fruit were infected naturally by $B$. cinerea (Figure 8 ). The most repeated UV-C treatment, "DURING", for which UV-C treatment was applied each week during all growth periods, was the most efficient at reducing natural contamination (a 288 reduction of $40 \%)$. The decrease observed for the other UV-C-treated samples was not significant compared to the control.

Moreover, during storage at $21^{\circ} \mathrm{C}$, strawberry fruit were also naturally infected by

Rhizopus sp. (Figure 9). After 4 days of storage, contamination with Rhizopus sp. was high in the control samples (55\%), and there was no difference with the treatment "AFTER". The "BEFORE" and "DURING" UV-C treatments significantly reduced the contamination after 4 days by $20 \%$ and $12 \%$, respectively.

\section{Impact of UV-C treatments on fruit quality}

297 hue angle and chroma of groups treated with UV-C were lower than those of the control 298 group. The groups "AFTER" and "DURING" had lower hue angles and chroma values than the 299 control group beginning at two days of storage. After three days of storage, the groups 300 "AFTER", "DURING" and "BEFORE" had a lower hue angle and chroma than the control group. 301 The firmness slightly decreased during storage for all the samples. 
with 30 consumers (Data not shown). UV-C treated fruit from both the "BEFORE" group and the "DURING" group were appreciated at the same level (21 \% for each group). The UV-C treated fruit from the "AFTER" group were appreciated by $11 \%$ of consumers. And $47 \%$ of consumers prefer fruit no treated with UV-C radiation.

\section{Discussion}

This study investigated the impact of pre-harvest application of UV-C radiation on plant growth, the sensitivity of leaves and fruit to major plant pathogens and fruit quality after harvest.

One striking result concerns the rate of flowering of strawberry plants between nontreated and UV-C treated plants. Flowering occurred earlier when strawberry plants received UV-C treatments. This result is consistent with two studies conducted by Darras et al. (2012a and 2015), who demonstrated that the application of short UV-C radiation improved flowering and even increased the biomass of geranium plants. Early flowering was also observed in strawberry plants treated with a low dose of UV-C at pre-harvest, which could be related to changes in the phytohormone profile (Xu et al., 2017a). If flowering occurs earlier, the production cycle can be completed faster, as shown in our study. Thus, larger amounts of ripe

320 fruit at harvest, especially for the strawberry plants treated before flowering, were counted.

321 It suggests that UV-C treatments were beneficial for flower initiation, allowing greater fruit 322 production. Floral induction results in the transition from the vegetative to the reproductive 323 state of meristem, under the action of a reduction in the gibberellin production. UV-C 324 treatments may have an impact on gibberellin production and thus promote flower induction. 
Fina et al. (2017) demonstrated that UV-B treatments on corn decreased leaf growth and this reduction was correlated with a decrease in the concentration of gibberellins. The floral

327 induction has given way to the floral initiation during which a certain number of stems was 328 initiated, thus determining a production potential. Floral differentiation was the last step. It is 329 this phase that determined flower number per stem and therefore fruit number (CTIFL, 2004). As the flowering process was rapid, UV-C treatments could be beneficial for all stages of flowering, from flower induction to flower differentiation and flower initiation. These results confirm that UV-C radiation can induce a high irradiance response that enhances plant growth and development of fruit (Taiz and Zeiger, 1998).

Crop quality is correlated with the accumulation of direct or indirect solar radiation, which is absorbed by the leaves and is dependent on the total area and number of leaves (Marcelis et al., 1998). In this study, we did not find significant differences in the amount of leaves per plant between non-treated and UV-C treated plants. A slight decrease in leaf area was observed for plants treated with UV-C. This result was in line with Darras et al. (2012a) who suggest that the UV-C radiation was powerful enough to give maximum benefits so that 340 plants did not need to expand their leaf area to capture more light radiation. Moreover, this 341 slight decrease in leaf area could be related to the flower induction with a decrease in 342 gibberellin content (Fina et al., 2017). In addition, analysis of parameters linked to chlorophyll 343 a fluorescence makes it possible to identify the potential damage caused by repeated and 344 successive UV-C treatments. In this study, we demonstrated that successive UV-C doses of $3451.70 \mathrm{~kJ} / \mathrm{m}^{2}$ did not damage the photosynthesis pathway. But the repetition of UV-C treatments 346 may improve the desired effect of UV-C radiation, that is, the stimulation of plant defenses. 347 Plants treated throughout cultivation (6 successive UV-C treatments) were less sensitive to $P$. 348 aphanis, B. cinerea and Rhizopus at the leaf and fruit level than plants treated once before 
349 flowering. An application threshold should therefore be found to improve plant resistance 350 without irreversibly damaging the photosynthetic system of plants. With a hormetic dose 351 applied to plants, the photosynthetic apparatus can be impacted, but reparation of this 352 pathway can occur after a few hours due to the photoreactivation of white light (Kunz et al., 353 2006).

Only a few reports have evaluated the impact of UV-C radiation when it was applied during plant growth (Darras et al., 2012a; Janisiewicz et al., 2016; Obande et al., 2011; Oliveira et al., 2016; Severo et al., 2016; Xie et al., 2015; Xu et al., 2019a). These studies focused on 357 the evolution of secondary metabolites in fruits and vegetables which is closely related to 358 defense mechanism. But limited knowledge is available regarding fruit responses to pathogens when UV-C radiation are applied before harvesting the fruit. This study investigated the impact of pre-harvest UV-C treatment on the susceptibility of strawberry plants and fruit. UV-C treatment applied after flowering significantly decreased the susceptibility of the 362 strawberry leaves to $B$. cinerea and to $P$. aphanis. For powdery mildew, the occurrence of a 363 natural epidemic does not make it possible to differentiate the part of the direct effect or the 364 induced resistance effect of UV-C in the high level of protection observed. UV-C radiation has 365 a well-known and studied direct antimicrobial effect. For example, Darras et al. (2012b) have 366 shown a strong impact of UV-C radiation on the conidial germination of $B$. cinerea and a 367 significant delay of mycelium growth. However, the decrease in the sensitivity of strawberry 368 plants which received a single UV-C radiation ("BEFORE"), long before the appearance of the 369 first symptoms of powdery mildew on untreated control plants, may indicate that induced 370 resistance occurred. 
$\mathrm{sp}$. and $B$. cinerea, demonstrating a potential link between pre-harvest treatments and post-

373 harvest conservation. However, after artificial inoculation with $B$. cinerea, we didn't observe any effect of UV-C treatments. The inoculation method of the fruit was probably too invasive,

causing $B$. cinerea to grow too quickly on the fruit, and not allowing identification of differences in susceptibility. Our inoculation method and that of Jin et al. (2017) were similar in the concentration of $B$. cinerea suspension $\left(10^{6} \mathrm{spores} / \mathrm{mL}\right.$ by wounding), but they observed that the strawberry fruit treated with UV-C had smaller lesion diameters. At least two hypothesis may explain the differences observed between our study and that of Jin et al: the strains of $B$. cinerea that may have different aggressiveness on strawberry and the temperature of incubation $\left(5^{\circ} \mathrm{C}\right.$ vs. $21^{\circ} \mathrm{C}$ in our study). At the temperature of $5^{\circ} \mathrm{C}$ used by Jin et al. (2017), the development of B. cinerea is slowed down (compared to the temperature of $21^{\circ} \mathrm{C}$ used during our experiment), and could explain the differences observed. during 4 days of storage at $21^{\circ} \mathrm{C}$. Color and firmness are widely used to monitor post-harvest fruit quality and are very well accepted as indicators of complex maturation processes and, therefore, of many physiological mechanisms (Gunness et al., 2009). The UV-C treatments did not alter the physical integrity of the strawberry fruit. In this study, there was no difference in firmness between fruit from control and UV-C-treated plants (from 1.7 to $10.20 \mathrm{~kJ} / \mathrm{m}^{2}$ ). This result is in contradiction with a previous study (Xie et al., 2016) that showed that pre-harvest UV-C treatments $\left(3.6 \mathrm{~kJ} / \mathrm{m}^{2}\right)$ improved the firmness of post-harvest strawberry fruit. According to these authors, this result depends on cultivar and season of harvesting that played a more important role in influencing fruit quality than the pre-harvest UV-C treatment. 
395 were redder (lower hue angle) in color than the control group. These results were in 396 agreement with those of Xu et al. (2017a), who demonstrated that the higher ABA level in 397 strawberry fruit treated with UV-C of low cumulative dose of $9.6 \mathrm{~kJ} / \mathrm{m}^{2}$ and mid-level 398 cumulative dose of $15 \mathrm{~kJ} / \mathrm{m}^{2}$, with more red color, suggests that UV-C dose stimulates the 399 accumulation of pigments such as anthocyanin. Other studies have shown that UV-C radiation 400 applied to plants during cultivation had an impact on the color of post-harvest strawberry 401 fruit. Xie et al. (2016) observed a significantly higher value for a*, which indicates redness. In 402 the case of strawberry fruit, these parameters generally indicate an increase in the anthocyanin content and are therefore a marker of the progress of fruit ripening. However,

404 Xie et al. (2015) did not observe any effect of pre-harvest UV-C on the anthocyanin content in 405 strawberry fruit.

We also conducted blind tests with a panel of 30 consumers to estimate the sensorial qualities of fruit. This study highlighted that UV-C treatment during pre-harvest did not change 408 the taste of fruit compared to the control if we took into account both UV-C treatments 409 ("CONTROL" vs "BEFORE"/"AFTER"/"DURING"). For this test, consumers did not prefer a 410 group, that is to say that strawberry were not sweeter for example as the sweetness is one of 411 the first quality parameter preferred by consumers.

\section{Conclusion}

In conclusion, pre-harvest UV-C treatments had some significant effect on plant and

415 reduced the natural occurrence of diseases, such as powdery mildew on leaves. Concerning 416 fruit, pre-harvest UV-C treatments had some significant effect on color and there was a strong 417 significant reduction in natural infection with pathogens, such as Rhizopus sp. Additional 
418 experiments will be done to confirm this encouraging result with artificial inoculum of 419 Rhizopus and P. aphanis.

It seems difficult to find only one UV-C treatment that would be optimal for all

421 parameters measured, such as disease resistance of plants, of fruit or fruit quality. In our

422 study, we showed that it is preferable to apply UV-C treatments before flowering to increase

423 flowering and plant yield but it is preferable to apply UV-C after flowering to reduce the

424 susceptibility of leaves to infection by $B$. cinerea. quality, but further evaluation is needed to find optimal UV-C treatments that can also have

427 an impact on strawberry fruit.

\section{Acknowledgements}

I would like to thank Tersys foundation for allowing me to carry out this research during knowledge.

\section{$434 \quad$ Literature Cited}

435 Aghdam, M.S., Jannatizadeh, A., Luo, Z., and Paliyath, G. 2018. Ensuring sufficient intracellular 436 ATP supplying and friendly extracellular ATP signaling attenuates stresses, delays senescence 437 and maintains quality in horticultural crops during postharvest life. Trends in Food Science and 438 Technology. 76:67-81. 
440 Bardin, M. and Gullino, M.L. 2020. Chapter 3: Fungal Diseases. In: Integrated Pest and Disease 441 Management in Greenhouse Crops, Plant Pathology in the 21st Century 9, Springer Nature 442 Switzerland AG., p.55-100.

443

444 Charles, M.T., Benhamou, N., and Arul, J. 2008. Physiological basis of UV-C induced resistance 445 to Botrytis cinerea in tomato fruit. III. Ultastructural modifications and their impact on fungal 446 colonization. Postharvest Biology and Technology. 47:41-53.

447

448 CTIFL 2004. Chapitre 2: Quelques rappels de physiologie, préparation et expression du 449 potentiel de production. In: La culture du fraisier sur substrat, p.22.

450

451 Darras, A.I., Demopoulos, V., Bali, I., and Tiniakou, C. 2012a. Photomorphogenic reactions in 452 geranium (Pelargonium $\times$ hortotum) plants stimulated by brief exposures of ultraviolet-C 453 irradiation. Plant Growth Regulation. 68:343-350.

454

455 Darras, A.I., Demopoulos, V., and Tiniakou, C. 2012b. UV-C irradiation induces defence 456 responses and improves vase-life of cut gerbera flowers. Postharvest Biology and Technology. $457 \quad 64(1): 168-174$. 
459

460

461

462

463

464

465

466

467

468

469

470 Erkan, M., Wang, S.Y., and Wang, C.Y. 2008. Effect of UV treatment on antioxidant capacity,

471 antioxidant enzyme activity and decay in strawberry fruit. Postharvest Biology and

472 Technology. 48:163-171.

473

474 Fina, J., Casadevall R., AbdElgawad, H., Prinsen, E., Markakis, M.N., Beemster, G.T.S., and

475 Casati, P. 2017. UV-B Inhibits Leaf Growth through Changes in Growth Regulating Factors and 476 Gibberellin Levels. Plant Physiology. 174:1110-1126. 
478 Forges, M., Vasquez, H., Charles, F., Chabane Sari, D., Urban, L., Lizzi, Y., Bardin, M., and 479 Aarrouf, J. 2018. Impact of UV-C radiation on the sensitivity of three strawberry plant cultivars 480 (Fragaria x ananassa) against Botrytis cinerea. Scientia Horticulturae. 240:603-613.

482 Freitas, P., Lopez-Galvez, F., Tudela, J., Gil, M., and Allende, A. 2015. Postharvest treatment of 483 table grapes with ultraviolet- $C$ and chitosan coating preserves quality and increases stilbene 484 content. Postharvest Biology and Technology. 105:51-57.

485 487 prevent decay and maintain postharvest quality of ripe "Tommy Atkins" mangoes. Journal of 488 Food Science and Technology. 36:767-773.

489

490 Gonzalez-Aguilar, G., Wang, C., and Buta, G. 2004. UV-C irradiation reduces breakdown and 491 chilling injury of peaches during cold storage. International Journal of Food Science and 492 Agriculture. 84:415-422.

493

494 Gonzalez-Aguilar, G., Zavaleta-Gatica, R., and Tiznado-Hernandez, M.E. 2007. Improving 495 postharvest quality of mango "Haden" by UV-C treatment. Postharvest Biology and 496 Technology. 45:108-116. 
498 Gunness, P., Kravchuk, O., Nottingham, S.M., D'Arcy, B.R., and Gidley, M.J. 2009. Sensory 499 analysis of individual strawberry fruit and comparison with instrumental analysis. Postharvest 500 Biology and Technology. 52:164-172

501

502

Hannum, S.M. (2004). Potential impact of strawberries on human health: a review of the 503 science. Critical Reviews in Food Science and Nutrition. 44:1-17.

504

505

Huang, H., Ge, Z., Limwachiranon, J., Li, L., Li, W., and Luo, Z. 2017. UV-C treatment affects 506 browning and starch metabolism of minimally processed lily bulb. Postharvest Biology and 507 Technology. 128:105-111.

508

509 Janisiewicz, W.J., Takeda, F., Nichols, B., Glenn, D.M., Jurick II, W.M., and Camp, M.J. 2016.

510 Use of low-dose UV-C irradiation to control powdery mildew caused by Podosphaera aphanis 511 on strawberry plants. Canadian Journal of Plant Pathology. 38(4):430-439.

513 Jin, P., Wang, H., Zhang, Y., Huang, Y., Wang, L., and Zheng, Y. 2017. UV-C enhances resistance 514 against gray mold decay caused by Botrytis cinerea in strawberry fruit. Scientia Horticulturae. $515 \quad 225: 106-111$.

517 Kunz, B.A., Cahill, D.M., Mohr, P.G., Osmond, M.J., and Vonarx, E.J. 2006. Plant Responses to 518 UV Radiation and Links to Pathogen Resistance. International Review of Cytology. 255, p.41. 
520 Li, D., Luo, Z., Mou, W., Wang, Y., Ying, T., and Mao, L. 2014. ABA and UV-C effects on quality, 521 antioxidant capacity and anthocyanins content of strawberry fruit (Fragaria $x$ ananassa 522 Duch.). Postharvest Biology and Technology. 90:56-62.

523

524 Li, D., Ye, Q., Jiang, L., and Luo, Z. 2017. Effects of nano-TiO2 packaging on postharvest quality 525 and antioxidant activity of strawberry (Fragaria $\times$ ananassa Duch.) stored at low temperature. 526 Journal of the Science of Food and Agriculture. 97:1116-1123.

527

528 Li, D., Zhang, X., Li, L., Aghdam, M.S., Wei, X., Liu, J., Xu, Y., and Luo, Z. 2019. Elevated $\mathrm{CO}_{2}$ 529 delayed the chlorophyll degradation and anthocyanin accumulation in postharvest strawberry 530 fruit. Food Chemistry. 285:163-170.

531

Liu, J., Stevens, C., Khan, V.A., Lu, J.Y., Wilson, C.L., Adeyeye, O., Kabwe, M.K., Pusey, P.L.,

533 Chalutz, E., Sultana, T., and Droby, S. 1993. The effect of ultraviolet-C light on storage rots and 534 ripening of tomatoes. Journal of Food Protection. 56:868-972. superatmospheric oxygen exposure on strawberry (Fragaria $\times$ ananassa Fuch.) volatiles, sensory and chemical attributes. Postharvest Biology and Technology. 142:60-71. 
540 Maharaj, R., Arul, J., and Nadeau, P. 1999. The Effect of photochemical treatment in the

541 preservation of fresh tomato (Lycopersicon esculentum cv. Capello) by delaying senescence.

542 Postharvest Biology and Technology. 15(1):13-23.

543

544 Marcelis, L.F.M., Heuveling, E., and Goudriaan, J. (1998). Modeling biomass production and 545 yield of horticultural crops: a review. Scientia Horticulturae. 74:83-111.

546

547 McGuire, R.G. 1992. Reporting objective color measurements. HortScience. 27(12):12545481255.

549

550 Mercier, J., Arul, J., Ponnampalam, R., and Boulet, M. 1993a. Induction of 6-methoxymellein 551 and resistance to storage pathogens in carrot slices by UV-C. Journal of Phytopathology. $552 \quad 137: 44-54$.

553

554 Mercier, J., Arul, J., and Julien, C. 1993b. Effect of UV-C on phytoalexin accumulation and 555 resistance to Botrytis cinerea in stored carrots. Journal of Phytopathology. 139:17-25.

556

557 Mercier, J., Baka, M., Reddy, B., Corcuff, R., and Arul, J. 2001. Shortwave Ultraviolet Irradiation 558 for Control of Decay Caused by Botrytis cinerea in Bell Pepper: Induced Resistance and 559 Germicidal Effects. Journal of the American Society for Horticultural Science. 126:128-133. 
561 Mohammadi, N., Mahammadi, S., Abdossi, V., Akbar, B., and Masoud, M. 2012. Effect of UV-

562 C radiation on antioxidant enzymes in strawberry fruit (Fragaria $x$ ananassa cv. Camarosa). 563 Journal of Agriculture and Biological Science. 7:860.

564

565 Obande, M.A., Tucker, G.A., and Shama, G. 2011. Effect of preharvest UV-C treatment of 566 tomatoes (Solanum lycopersicon Mill.) on ripening and pathogen resistance. Postharvest 567 Biology and Technology. 62:188-192.

568

569 Oliveira, I.R., Crizel, G.R., Severo, J., Renard, C.M.G.C., Chaves, F.C., and Rombaldi, C.V. 2016. 570 Preharvest UV-C radiation influences physiological, biochemical, and transcriptional changes 571 in strawberry cv. Camarosa. Plant Physiology and Biochemistry. 108:391-399.

572

573 Ouhibi, C., Attia, H., Rebah, F., Msilini, N., Chebbi, M., Aarrouf, J., Urban, L., and Lachaal, M. 574 2014. Salt stress mitigation by seed priming with UV-C in lettuce plants: growth, antioxidant 575 activity and phenolic compounds. Plant Physiology and Biochemistry. 83:126-133.

576

577 Ouhibi, C., Attia, H., Nicot, P., Lecompte, F., Vidal, V., Lachaâl, M., Urban, L., and Aarrouf, J. 578 2015. Effects of nitrogen supply and of UV-C irradiation on the susceptibility of Lactuca sativa 579 L. to Botrytis cinerea and Sclerotinia minor. Plant and Soil. 393:35-46. 
581 Pascal, F., Forges, M., Bastien, J.M., Charles, F., Aarrouf, J., and Bardin, M. 2018. Fabrication

582 d'une enceinte UV-C pour le traitement des plantes. Cahier des techniques de I'INRA. 93.

583

584 Perkins-Veazie, P. 1995. Growth and ripening of strawberry fruit. Horticultural Reviews.

$585 \quad$ 17:265-297.

586

587 Poiroux-Gonord, F., Bidel, L.P.R., Fanciullino, A.L., Gautier, H., Lauri-Lopez, F., and Urban, L.

588 2010. Health Benefits of Vitamins and Secondary Metabolites of Fruit and Vegetables and

589 Prospects To Increase Their Concentrations by Agronomic Approaches. Journal of Agricultural

$590 \quad$ Food and Chemistry. 58:12065-12082.

591

592 Pombo, M.A., Dotto, M.C., Martínez, G.A., and Civello, P.M. 2009. UV-C irradiation delays 593 strawberry fruit softening and modifies the expression of genes involved in cell wall 594 degradation. Postharvest Biology and Technology. 51:141-148.

595

596 Pombo, A., Rosli, G., Martinez, A., and Civello, M. 2011. UV-C treatment affects the expression 597 and activity of defense genes in strawberry fruit (Fragaria $x$ ananassa Duch.). Postharvest 598 Biology and Technology. 59:94-102. 
600 601 602 603

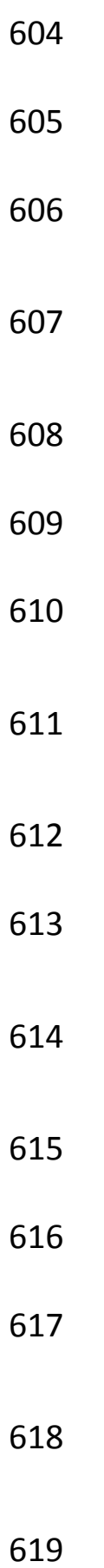
604
605
606
607
608
609
610
611
612
613
613
614

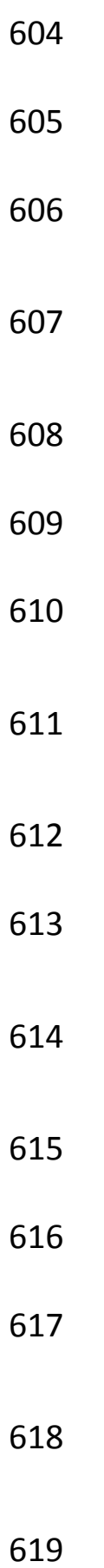

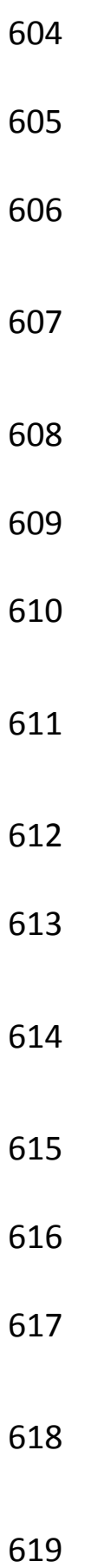

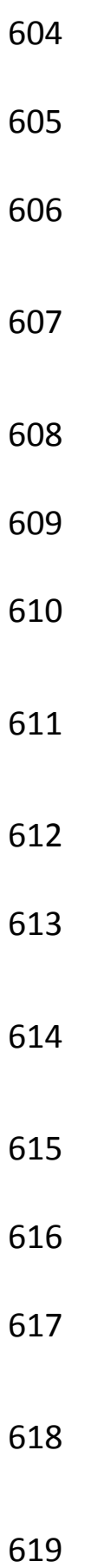

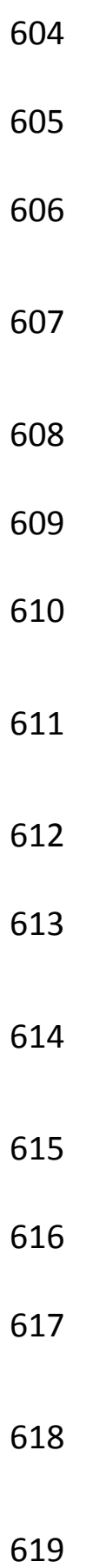

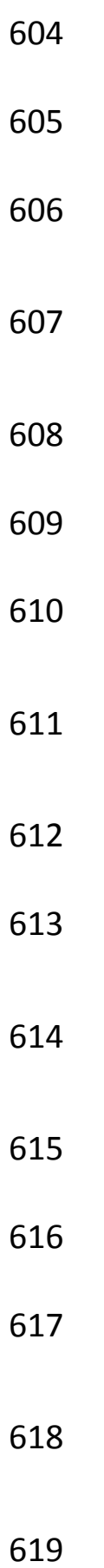

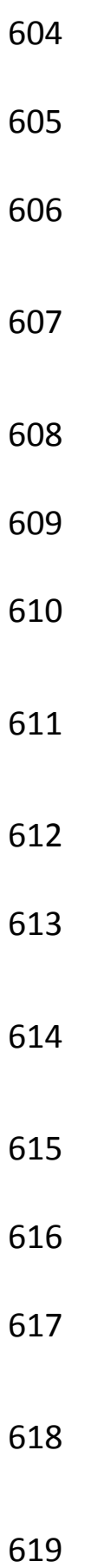

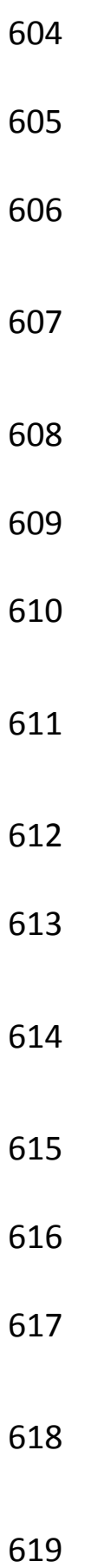

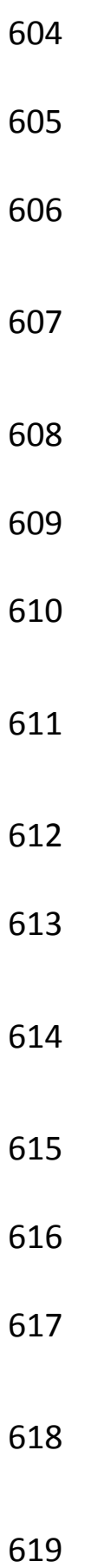

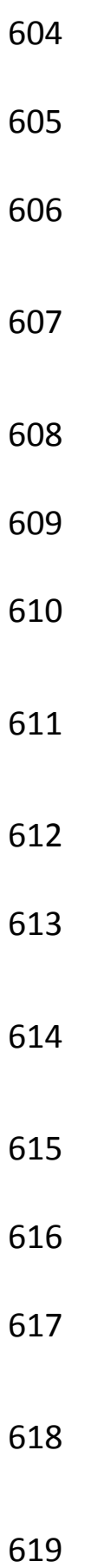

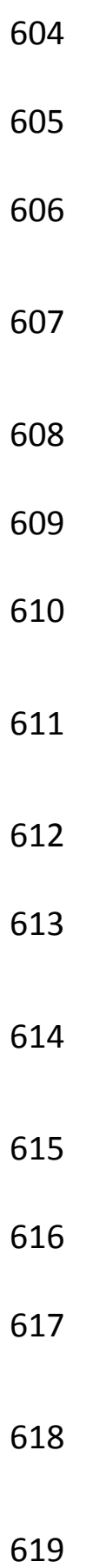

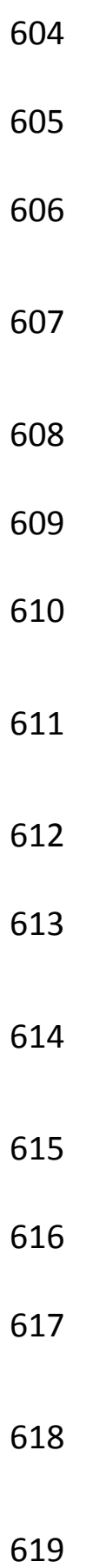

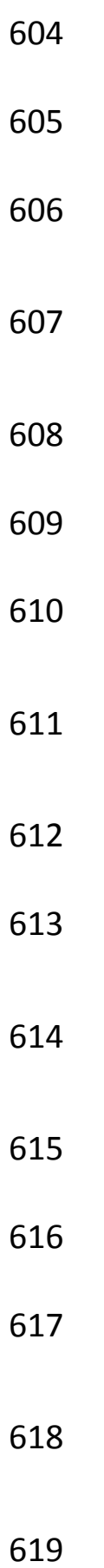

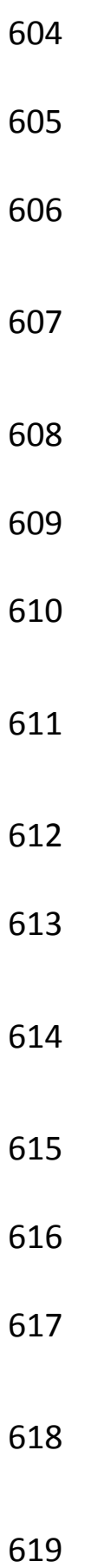

611
Severo, J., Oliveira, I.R., Bott, R., Le Bourvellec, C., Renard, C.M.G., Page, D., Chaves, F.C., and Rombaldi, C.V. 2016. Preharvest UV-C radiation impacts strawberry metabolite content and volatile organic compound production. Food Science and Technology. 1-4.

Siddiqui, A., Dawar, S., Zaki, M.J., and Hamid, N. 2011. Role of ultra violet (UV-C) radiation in the control of root infecting fungi on groundnut and mung bean. Pakistan Journal of Botany. 43:2221-2224.

Stevens, C., Khan, V.A., Tang, A.Y., and Lu, J.Y. 1990. The effect of ultraviolet radiation on mold rots and nutrients of stored sweet potatoes. Journal of Food Protection. 53:223-226.

Stirbet, A., and Govindjee, 2011. On the relation between the Kautsky effect (chlorophyll a fluorescence induction) and Photosystem II: basics and applications of the OJIP fluorescence transient. Journal of Photochemistry and Photobiology B. 104:236-257.

Taiz, L., and Zeiger, E. (1998). Plant Physiology. Second ed. Sinauer Associates, Inc., Publishers, Massachusetts, USA. 
622 Terry, L.A., and Joyce, D.C. 2004. Elicitors of induced disease resistance in postharvest

623 horticultural crops: a brief review. Postharvest Biology and Technology. 32:1-13.

624

625 Urban, L., Charles, F., de Miranda, M.R.A., and Aarrouf, J. 2016. Understanding the 626 physiological effects of UV-C light and exploiting its agronomic potential before and after 627 harvest. Plant Physiology and Biochemistry. 105:1-11.

628

629 Vasquez, H., Ouhibi, C., Forges, M., Azzouz, N., Bardin, M., Lizzi, Y., Nicot, P., Urban, L., and 630 Aarrouf, J. 2017. Pre-harvest hormetic doses of UV-C radiation can decrease susceptibility of 631 lettuce leaves (Lactuca sativa L.) to Botrytis cinerea. Scientia Horticulturae. 222:32-39.

632

633 Xie, Z., Charles, M.T., Fan, J., Charlebois, D., Khanizadeh, S., Rolland, D., Roussel, D., 634 Deschenes, M., and Dubé, C. 2015. Effects of preharvest ultraviolet-C irradiation on fruit 635 phytochemical profiles and antioxidant capacity in three strawberry (Fragaria $x$ ananassa 636 Duch.) cultivars. Journal of the Science of Food and Agriculture. 95:2996-3002.

637

638 Xie, Z., Fan, J., Charles, M.T., Charlebois, D., Khanizadeh, S., Rolland, D., Roussel, D., and Zhang, 639 Z. 2016. Preharvest ultraviolet-C irradiation: influence on physicochemical parameters 640 associated with strawberry fruit quality. Plant Physiology and Biochemistry. 108:337-343. 
642 Xu, Y., Charles, M.T., Luo, Z., Roussel, D., and Rolland, D. 2017a. Potential link between fruit 643 yield, quality parameters and phytohormonal changes in preharvest UV-C treated strawberry. 644 Plant Physiology and Biochemistry. 116:80-90.

645

646 Xu, Y., Luo, Z., Charles, M.T., Rolland, D., and Roussel, D. 2017b. Pre-harvest UV-C irradiation 647 triggers VOCs accumulation with alteration of antioxidant enzymes and phytohormones in 648 strawberry leaves. Journal of Plant Physiology. 218:265-274.

649

650 Xu, Y., Charles, M.T., Luo, Z., Mimee, B., Tong, Z., Véronneau, P.Y., Rolland, D., and Roussel, D. 651 2018. Preharvest ultraviolet $C$ treatment affected senescence of stored strawberry fruit with 652 a potential role of microRNAs in the activation of the antioxidant system. Journal of 653 Agricultural and Food Chemistry. 66:12188-12197.

654

655 Xu, Y., Charles, M.T., Luo, Z., Mimee, B., Tong, Z., Roussel, D., Rolland, D., and Véronneau, P.Y. 656 2019a. Preharvest UV-C treatment affected postharvest senescence and phytochemicals 657 alternation of strawberry fruit with the possible involvement of abscisic acid regulation. Food 658 Chemistry. 299:125-138.

659

660 Xu, Y., Charles, M.T., Luo, Z., Mimee, B., Chao, T., Veronneau, P.Y., Rolland, D., and Roussel, D. 661 2019b. Ultraviolet-C priming of strawberry leaves against subsequent Mycosphaerella 662 fragariae infection involves the action of reactive oxygen species, plant hormones, and 663 terpenes. Plant Cell and Environment. 42:815-831. 
664

665 Yan, J., Luo, Z., Ban, Z., Lu, H., Li, D., Yang, D., Aghdam, M.S., and Li, L. 2019. The effect of the 666 layer-by-layer (LBL) edible coating on strawberry quality and metabolites during storage. 667 Postharvest Biology and Technology. 147:29-38.

668

669 Yang, Z., Cao, S., Su, X., and Yueming, J. 2014. Respiratory activity and mitochondrial 670 membrane associated with fruit senescence in postharvest peaches in response to UV-C 671 treatment. Food Chemistry. 161:16-21. 
(A)

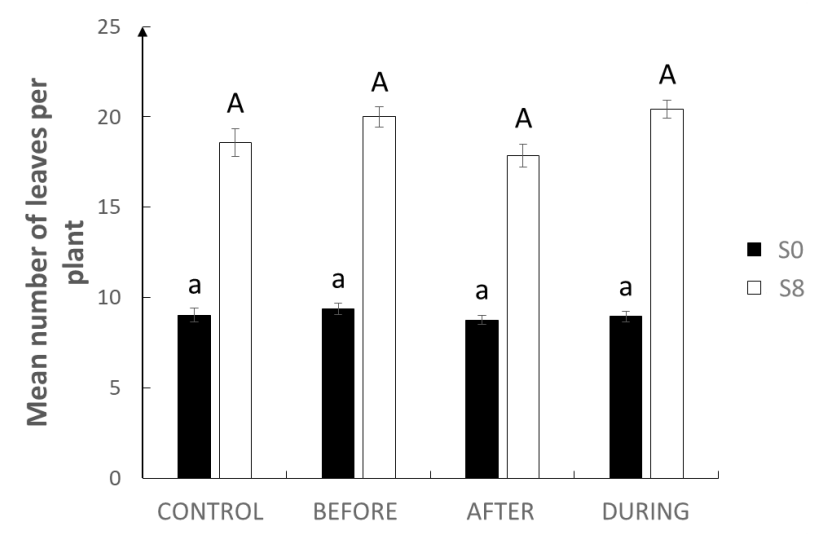

(B)

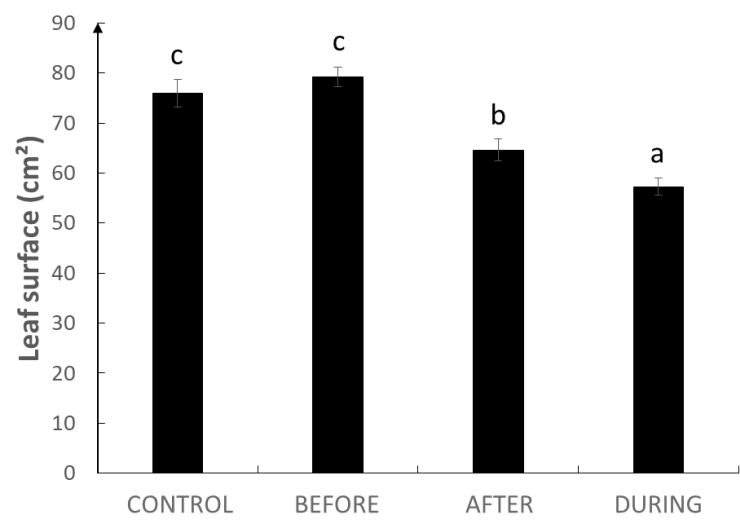

Figure 1: Effect of UV-C treatment on (A) the number of leaves per plant and (B) the leaf surface at harvest. "CONTROL" corresponds to plants without treatment, "BEFORE" corresponds to UV-C treatment realized before flowering, "AFTER" corresponds to UV-C treatment realized after flowering and "DURING" corresponds to UV-C treatment realized throughout the crop. The selected UV-C dose is $1.70 \mathrm{~kJ} / \mathrm{m}^{2}$. (A) Count of leaves was done before the first UV-C treatments, after 15 days of plant growth (SO) and at harvest (S8), after the successive UV-C treatments $(n=47)$. (B) Leaf surface was measured at harvest day $(n=47)$. Different letters indicate significant differences according to Newman-Keuls test at $p<0.05$. 


\begin{tabular}{|c|c|c|c|}
\hline AUFC & BEFORE & AFTER & DURING \\
\hline Area & 21.63 & -16.86 & -11.90 \\
\hline Fo & 0.95 & -11.64 & -10.57 \\
\hline $\mathrm{Fm}$ & -0.18 & $\underline{-13.01}$ & -15.81 \\
\hline $\mathrm{Fv}$ & -0.40 & -13.28 & -16.83 \\
\hline $\mathrm{FO} / \mathrm{Fm}$ & 1.56 & 1.71 & 6.38 \\
\hline $\mathrm{Fv} / \mathrm{Fm}$ & -0.30 & -0.33 & -1.24 \\
\hline $\mathrm{Fv} / \mathrm{FO}$ & -1.35 & -1.83 & $\underline{-7.15}$ \\
\hline $\mathrm{Sm}$ & $\underline{14.85}$ & -4.82 & 5.53 \\
\hline $\mathrm{N}$ & 10.91 & -10.79 & -0.22 \\
\hline ABS / RC & -5.15 & -6.08 & -4.09 \\
\hline $\mathrm{Di0} / \mathrm{RC}$ & -3.69 & -4.06 & 1.77 \\
\hline TRO / RC & $\underline{-5.43}$ & $\underline{-6.48}$ & $\underline{-5.24}$ \\
\hline Eto / RC & $\underline{-7.58}$ & -7.09 & -4.89 \\
\hline $\mathrm{Re} 0 / \mathrm{RC}$ & $\underline{-4.16}$ & -10.54 & $\underline{-4.83}$ \\
\hline Pi total & 7.08 & -1.60 & -1.52 \\
\hline$\left(1-V_{i}\right) /\left(1-V_{j}\right)$ & $\underline{3.23}$ & $\underline{-3.48}$ & 0.20 \\
\hline $1-(\mathrm{F} 4 / \mathrm{Fm})$ & $\underline{-2.97}$ & -0.78 & -0.90 \\
\hline $\mathrm{Vk} / \mathrm{Vj}$ & -9.66 & -7.60 & -4.29 \\
\hline
\end{tabular}

\begin{tabular}{|l|l|l|l|l|}
\hline-25 & -10 & 0 & 10 & 25 \\
\hline
\end{tabular}

Figure 2: Relative fluorescence of chlorophyll a of strawberry plant at the harvest day. "BEFORE" corresponds to UV-C treatment realized before flowering, "AFTER" corresponds to UV-C treatment realized after flowering and "DURING" corresponds to UV-C treatment realized throughout the crop. The selected UV-C dose is $1.70 \mathrm{~kJ} / \mathrm{m}^{2}$. Values represented AUFC (Area Under Fluorescence Curve) and represent difference percentages between each group treated with UV-C compared to the control group ( $n=145)$. A color scale is provided, ranging from red (negative effect of UV-C radiation) to green (positive effect of UV-C radiation). Values in bold and underlined mean significant difference according to the Newman-Keuls test at $p$-value $<0.05$ ). 
(A)

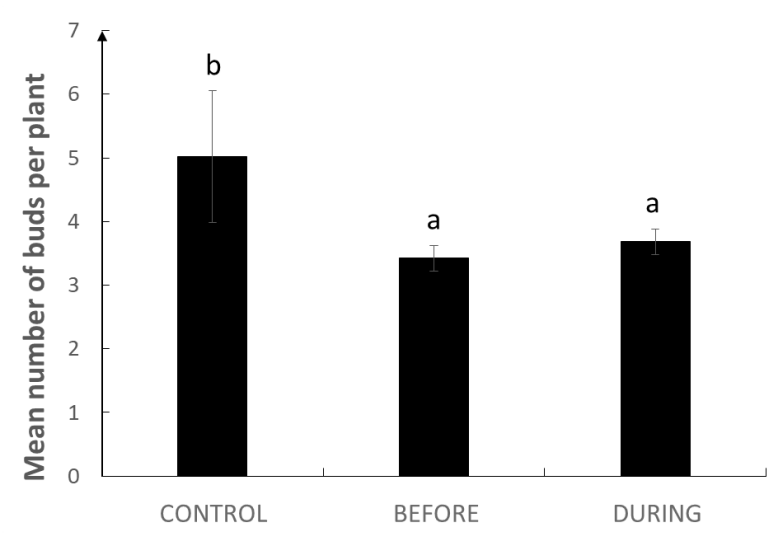

(B)

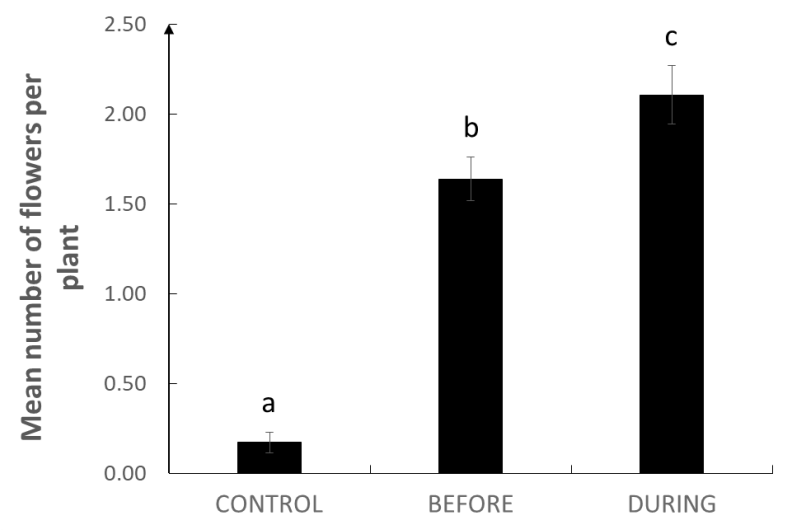

Figure 3: Effect of UV-C treatment on the number of (A) buds and (B) flowers per plant (counted one week after the first UV-C treatment). This count was done before flower apparition $(n=47)$. "CONTROL" corresponds to plants without treatment, "BEFORE" corresponds to UV-C treatment realized before flowering and "DURING" corresponds to UV-C treatment realized throughout the crop. Groups "BEFORE" and "DURING" corresponded to the same modality at this level because the count was done before flowering (group "AFTER" didn't take into account because because it was after UVC treatment on modalities "BEFORE" and "DURING"). The selected UV-C dose is $1.70 \mathrm{~kJ} / \mathrm{m}^{2}$. Different letters indicate significant differences according to the Newman-Keuls test at $p$-value $<0.05$. 


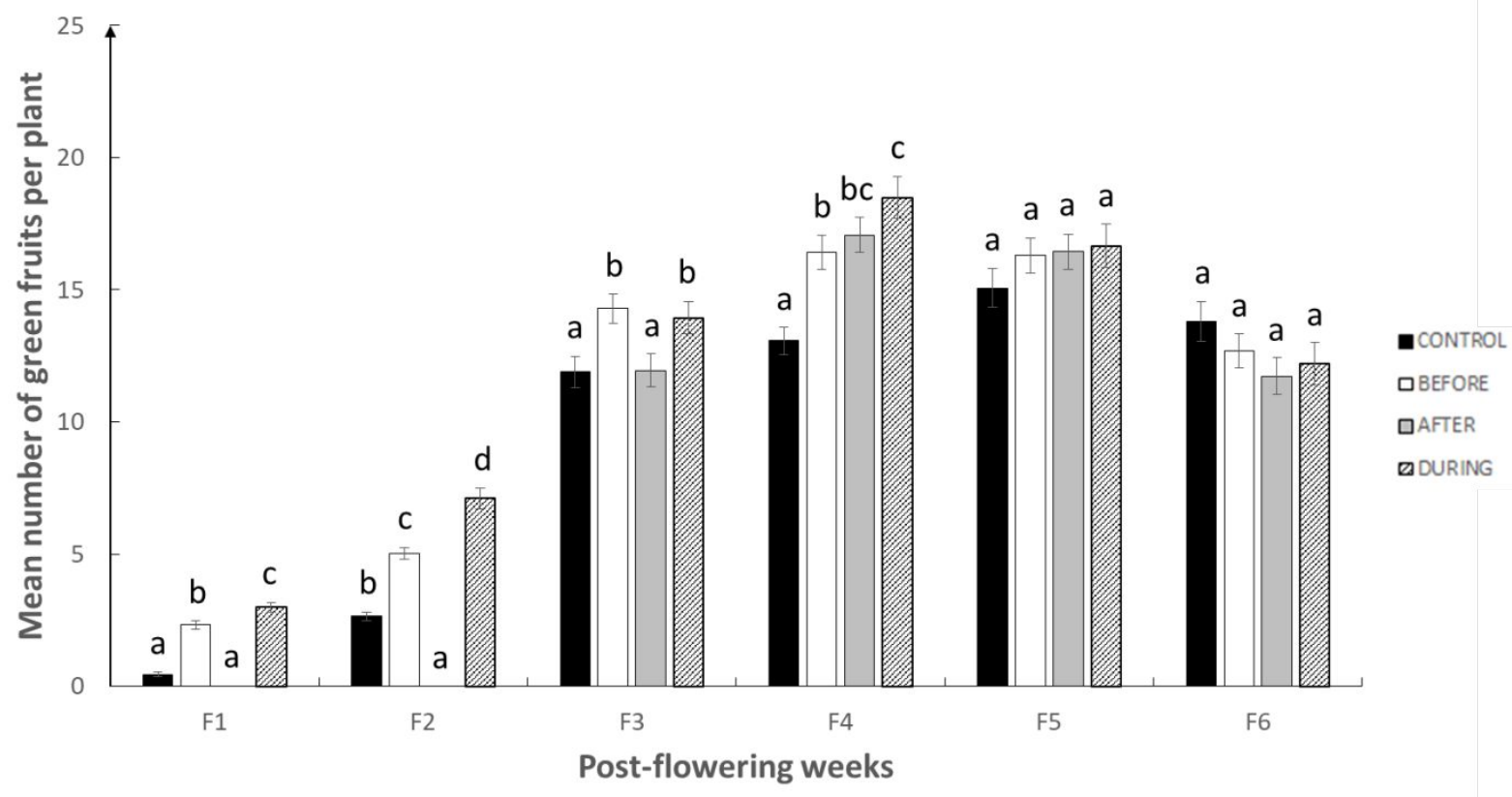

Figure 4: Mean number of green fruit produced per strawberry plant during the cultivation. "CONTROL" corresponds to plants without treatment, "BEFORE" corresponds to UV-C treatment realized before flowering, "AFTER" corresponds to UV-C treatment realized after flowering and "DURING" corresponds to UV-C treatment realized throughout the crop. The selected UV-C dose is $1.70 \mathrm{~kJ} / \mathrm{m}^{2}$. Count was made during 6 weeks just after flowering (post-flowering weeks $=\mathrm{F}$ ) on each strawberry plant $(n=47)$. Different letters indicate significant differences according to Newman-Keuls test at $p$-value $<0.05$. 
(A)

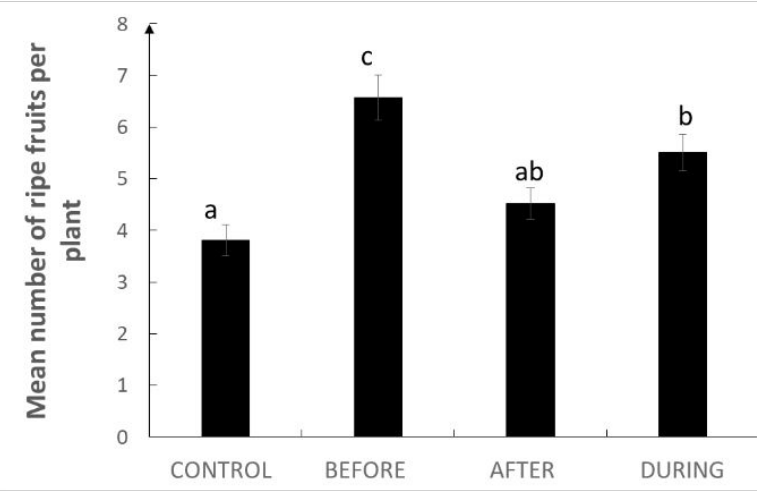

(B)

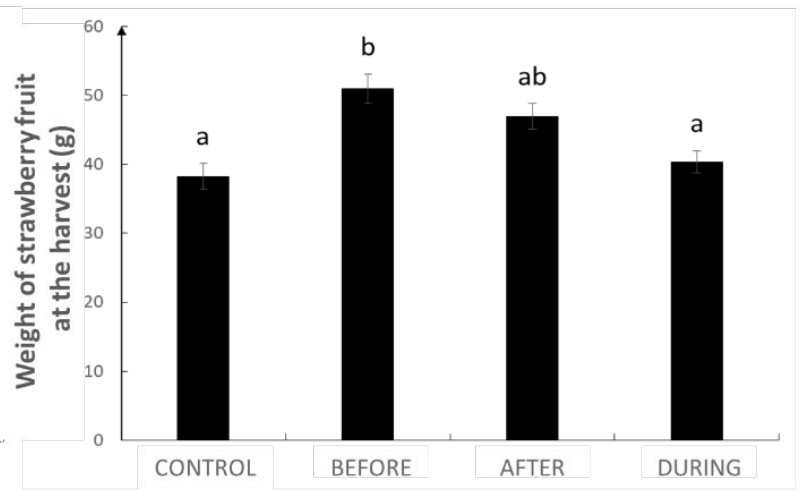

Figure 5: (A) Number of ripped fruit per strawberry plant at harvest (one week after the last UV-C treatment). (B) Effect of UV-C treatment on the weight of strawberry fruit at harvest (one week after the last UV-C treatment). "CONTROL" corresponds to plants without treatment, "BEFORE" corresponds to UV-C treatment realized before flowering, "AFTER" corresponds to UV-C treatment realized after flowering and "DURING" corresponds to UV-C treatment realized throughout the crop. The selected UV-C dose is $1.70 \mathrm{~kJ} / \mathrm{m}^{2}$. (A) The count was done on each strawberry plant $(n=47)$ and (B) The weight of strawberry fruit was done on 20 fruit per modality. Different letters indicate significant differences according to Newman-Keuls test at $p$-value $<0.05$. 
A

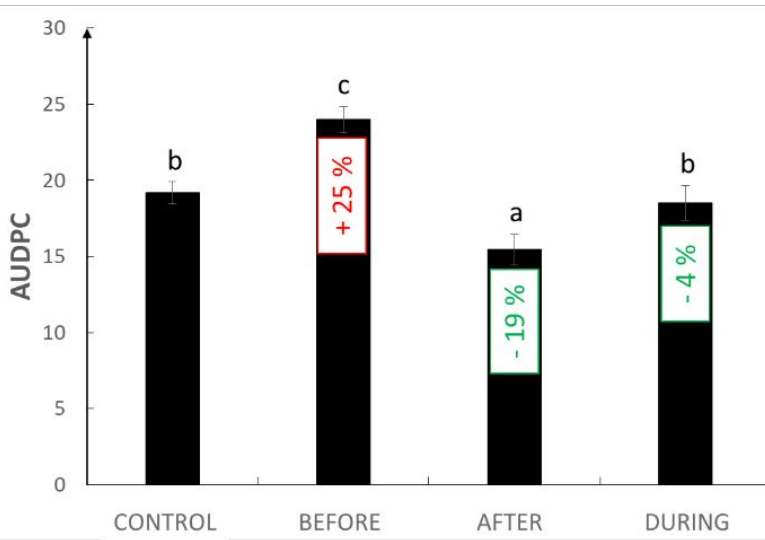

B

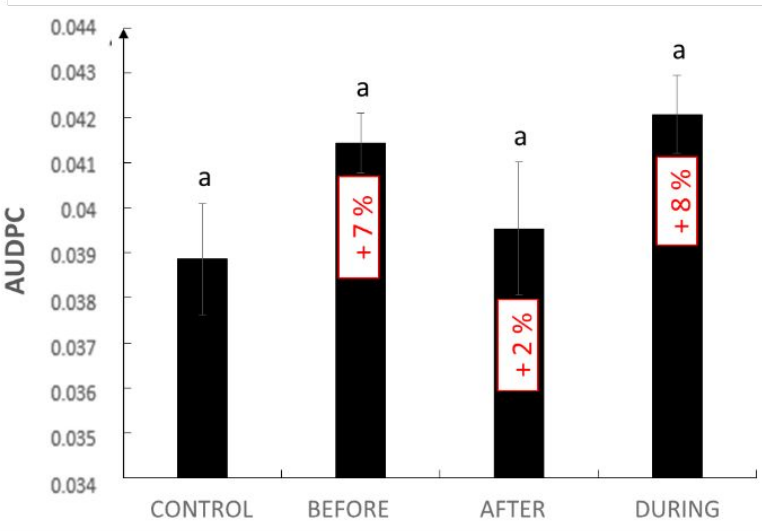

Figure 6: Susceptibility of strawberry leaves (A) and strawberry fruit (B) to B. cinerea. "CONTROL" corresponds to plants without treatment, "BEFORE" corresponds to UV-C treatment realized before flowering, "AFTER" corresponds to UV-C treatment realized after flowering and "DURING" corresponds to UV-C treatment realized throughout the crop. The selected UV-C dose is $1.70 \mathrm{~kJ} / \mathrm{m}^{2}$. Inoculation of leaves were made after UV-C treatments by deposing a mycelial plug of $B$. cinerea on the main vein of detached leaves. Surface of necrosis was measured daily for 6 days in order to calculate the AUDPC (Area Under Disease Progression Curve, $n=47$ ). Inoculations of fruit were carried out by depositing a drop of fungus suspension at $10^{6} \mathrm{spore} / \mathrm{mL}$. Measurement of necrosis width was done daily for 4 days in order to calculate AUDPC $(n=18)$. Percentages correspond to the protection or sensibility level compared to the control group: in red depict acceleration of the disease progression curve and percentages indicated in green its slowing down (protection). Different letters indicate significant differences according to Newman-Keuls test at (A) $p$-value $<0.01$ and (B) $p$-value $=0.05$. 


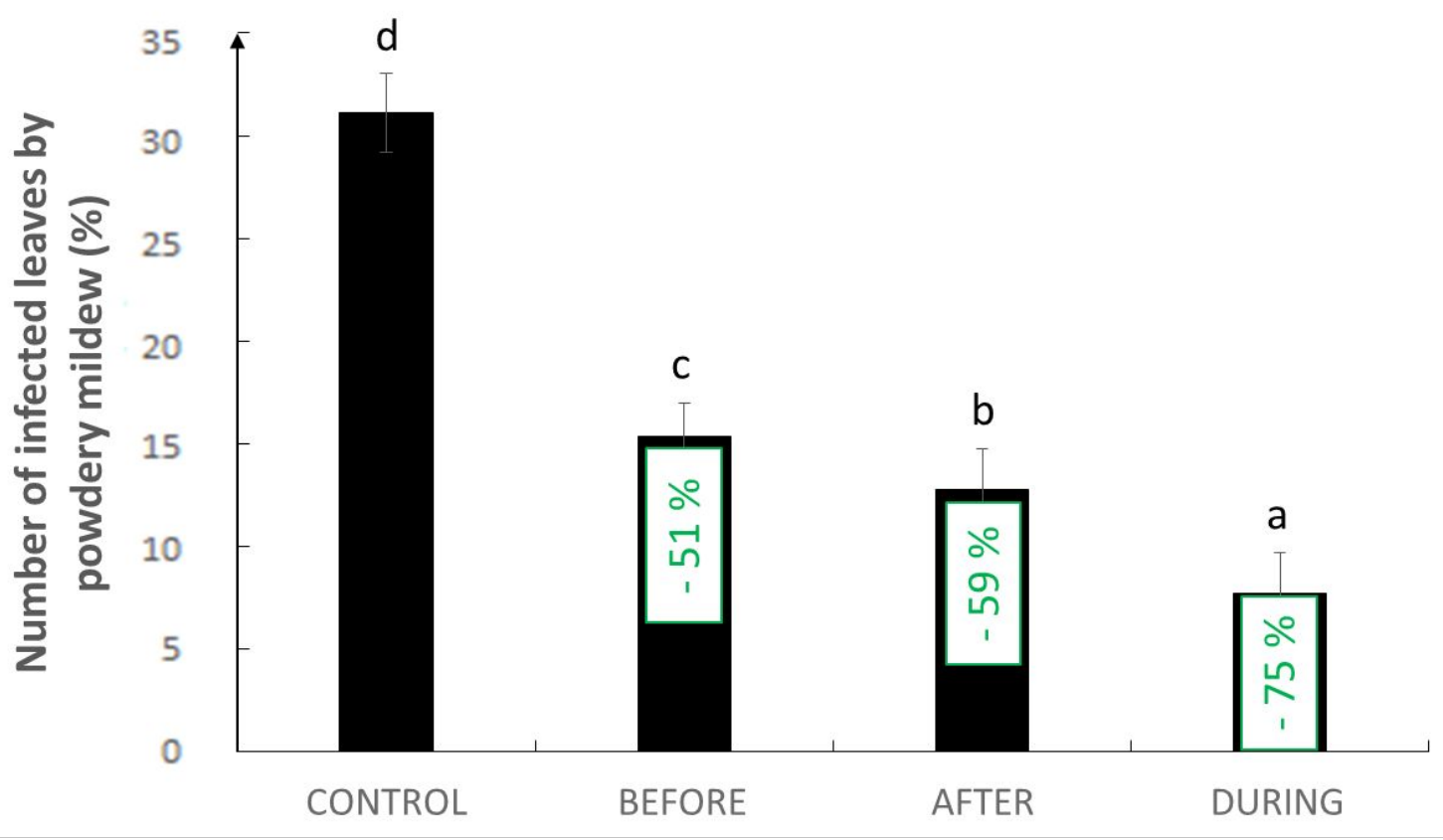

Figure 7: Susceptibility of strawberry leaves to powdery mildew. "CONTROL" corresponds to plants without treatment, "BEFORE" corresponds to UV-C treatment realized before flowering, "AFTER" corresponds to UV-C treatment realized after flowering and "DURING" corresponds to UV-C treatment realized throughout the crop. The selected UV-C dose is $1.70 \mathrm{~kJ} / \mathrm{m}^{2}$. Amount of leaves with symptoms was estimated by appearance of powdery and whitish leaf spots $(n=47)$. Different letters indicate significant differences according to Newman-Keuls test at $p$-value $<0.0001$. 


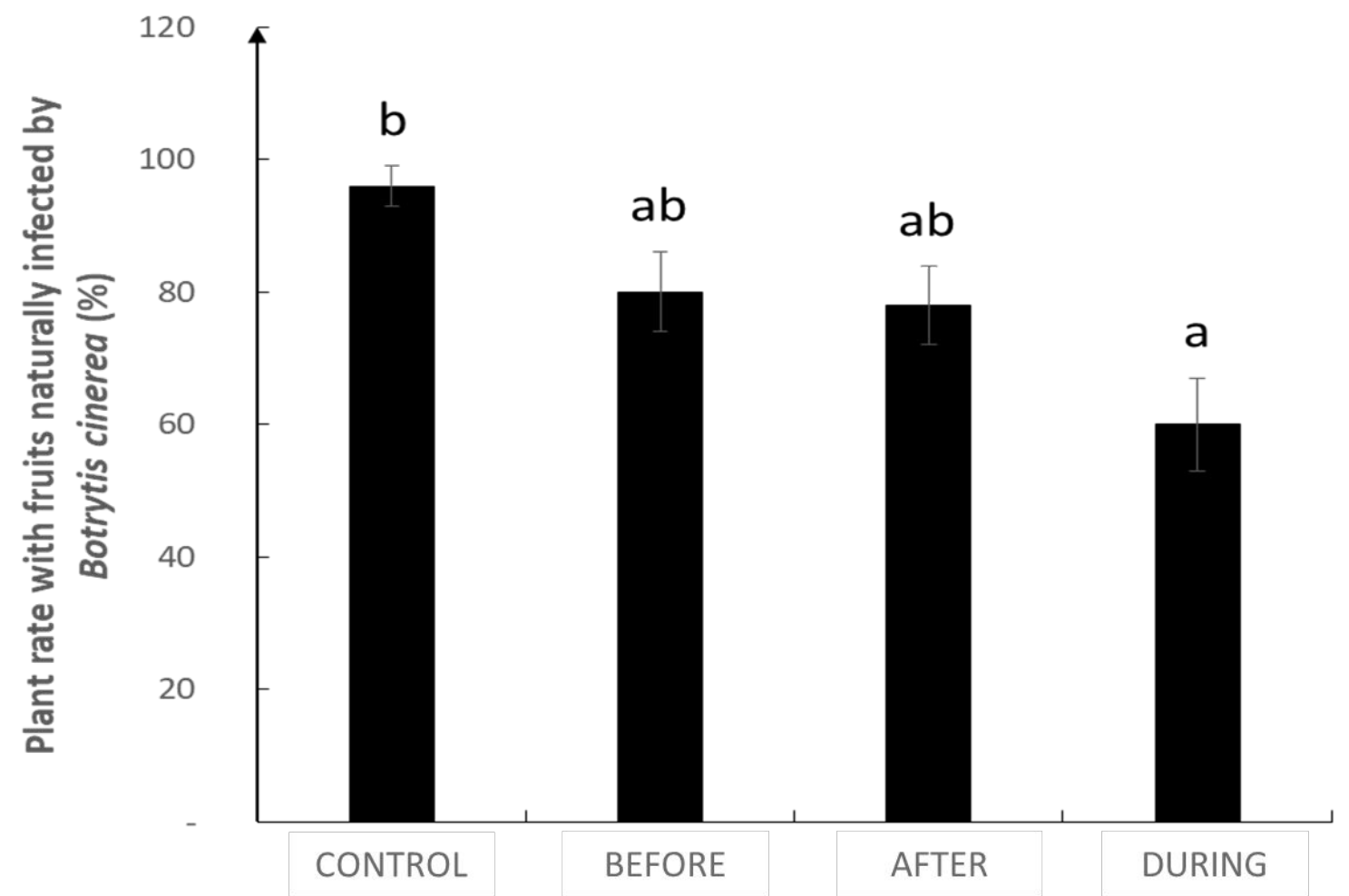

Figure 8: Plants with fruit naturally infected by B. cinerea (\%). "CONTROL" corresponds to plants without treatment, "BEFORE" corresponds to UV-C treatment realized before flowering, "AFTER" corresponds to UV-C treatment realized after flowering and "DURING" corresponds to UV-C treatment realized throughout the crop. The selected UV-C dose is $1.70 \mathrm{~kJ} / \mathrm{m}^{2}$. The presence or absence of $B$. cinerea on strawberry fruit was evaluated and the percentage of strawberry plants with at least one infected fruit was computed $(n=47)$. Different letters indicate significant differences according to $\mathrm{Khi}^{2}$ test at $p$-value $<0.05$. 


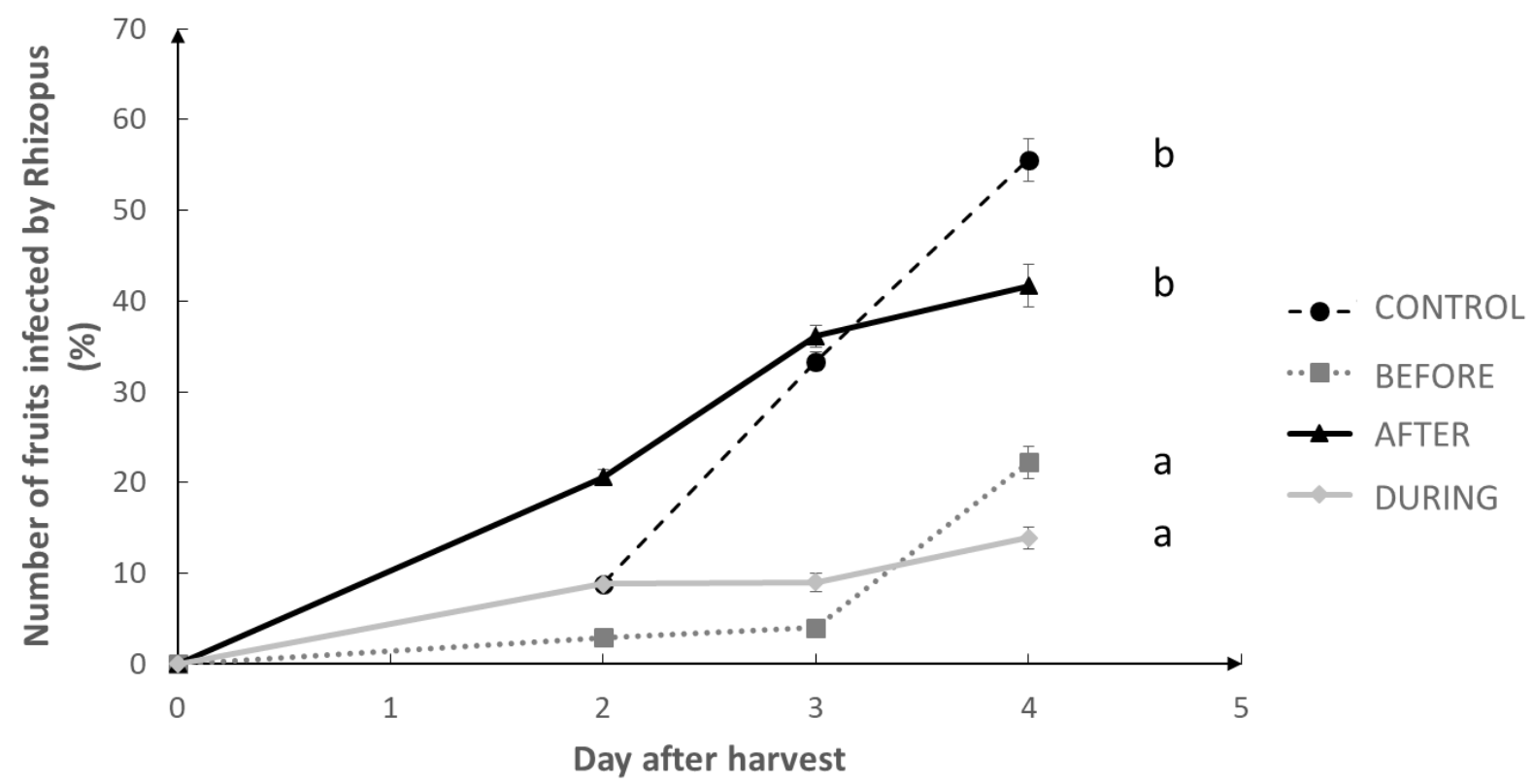

Figure 9: Susceptibility of strawberry fruit to Rhizopus sp. during fruit storage. "CONTROL" corresponds to plants without treatment, "BEFORE" corresponds to UV-C treatment realized before flowering, "AFTER" corresponds to UV-C treatment realized after flowering and "DURING" corresponds to UV-C treatment realized throughout the crop. The selected UV-C dose is $1.70 \mathrm{~kJ} / \mathrm{m}^{2}$. A follow-up of fruit infected with Rhizopus sp. was carried out every day and the percentage of infected fruit was calculated $(n=18)$. Different letters indicate significant differences according to Newman-Keuls test at p-value $<0.05$. 
Table 1: Evolution of color (Hue and Chroma) and firmness of strawberry. "CONTROL" corresponds to plants without treatment, "BEFORE" corresponds to UV-C treatment realized before flowering, "AFTER" corresponds to UV-C treatment realized after flowering and "DURING" corresponds to UV-C treatment realized throughout the crop. The selected UV-C dose is $1.70 \mathrm{~kJ} / \mathrm{m}^{2}$. The firmness and color were done on 18 fruit per modality. Color were estimated with Hue angle $\left(\mathrm{H}^{\circ}\right.$, where $0^{\circ}=$ red-purple, $90^{\circ}=$ yellow, $180^{\circ}=$ bluish-green, and $270^{\circ}=$ blue) and Chroma $\left(C^{*}\right.$, which represents the intensity of color) thanks to $L^{*} a^{*} b^{*}$ parameters (McGuire, 1992). The $\left(^{*}\right)$ shows statistical differences between modalities according to Newman-Keuls test at $p$-value $<0.05$.

COLOR

FIRMNESS

\begin{tabular}{|c|c|c|c|c|c|c|c|c|c|}
\hline & \multicolumn{6}{|c|}{ COLOR } & \multicolumn{3}{|c|}{ FIRIVINESS } \\
\hline & \multicolumn{3}{|c|}{ Hue $\mathrm{H}^{\circ}$} & \multicolumn{3}{|c|}{ Chroma C* } & \multirow[b]{2}{*}{0} & \multirow[b]{2}{*}{2} & \multirow[b]{2}{*}{4} \\
\hline & 0 & 2 & 4 & 0 & 2 & 4 & & & \\
\hline CONTROL & $29.2 \pm 0.8$ & $33.3 \pm 1.0$ & $34.0 \pm 1.1$ & $43.1 \pm 1.0$ & $41.1 \pm 1.8$ & $46.5 \pm 1.0$ & $4.2 \pm 0.6$ & $3.9 \pm 0.3$ & $3.4 \pm 0.3$ \\
\hline BEFORE & $28.3 \pm 1.3$ & $31.5 \pm 0.7$ & $30.3^{*} \pm 0.9$ & $42.3 \pm 1.0$ & $42.0 \pm 1.2$ & $43.1 \pm 0.9$ & $4.4 \pm 0.7$ & $4.2 \pm 0.3$ & $3.2 \pm 0.1$ \\
\hline AFTER & $26.7 \pm 1.9$ & $26.0 * \pm 0.5$ & $27.6 * \pm 0.5$ & $38.6 \pm 1.4$ & $33.5 \pm 0.9$ & $39.4 \pm 0.7$ & $4.1 \pm 0.6$ & $4.1 \pm 0.3$ & $3.3 \pm 0.2$ \\
\hline DURING & $25.8 \pm 1.2$ & $26.1 * \pm 0.7$ & $25.7 * \pm 1.2$ & $37.7 \pm 1.3$ & $35.1 \pm 1.3$ & $40.5 \pm 1.3$ & $4.2 \pm 0.4$ & $4.3 \pm 0.4$ & $3.2 \pm 0.2$ \\
\hline
\end{tabular}

